\title{
Diagnostic Specificity
}

National Cancer Institute

\section{Source}

National Cancer Institute. Diagnostic Specificity. NCI Thesaurus. Code C41395.

The probability that a test will produce a true negative result when used on non-effected subjects as compared to a reference or "gold standard". The specificity of a test can be determined by calculating: number of true negative results divided by the sum of true negative results plus number of false positive results. 